\title{
FROM PROTECTING CROPS TO PROTECTING AGRICULTURAL PRODUCTION SYSTEMS
}

\author{
Louise O. Fresco \\ Wagningen Agricultural University \\ Department of Agronomy \\ P.O.Box 341 \\ $6700 \mathrm{AH}$ Wageningen \\ The Netherlands \\ phone: +31317482513 \\ fax: $\quad+31317484575$ \\ email: louise.fresco@trop.agro.wau.nl
}

In the late 1960s - about a generation ago - when I entered Wageningen University as a first year student, the perspective for an agricultural scientist was rather uncomplicated. In Northwestern Europe, agriculture represented a respected sector of the economy that had helped to materialise the rapid recovery after the second world war, due to unprecedented increase in its labour productivity. Also in other temperate climate zones, with the notable exception of Eastern Europe, yields and labour productivity were steadily increasing. In developing countries, the problems were of course severe, and the images of widespread starvation and poverty, particularly in Asia, motivated many students of my generation to study agricultural science, even if they were not born on a farm.

The Green Revolution had just started to make its way: modern high yielding varieties spread rapidly from about 1965 onwards. The potential of yield increase seemed beyond doubt. The 1970s were therefore a decade of optimism, of unbridled belief in the blessings of agricultural technology. Although complex, the scientific mandate was straightforward: to increase the yield potential of new genotypes, improve host plant resistance and to minimize genotype-environment interactions in order to develop technologies suitable for wide adoption.

Plant protection, so closely associated with the development of modern varieties, played an important part in that general feeling of optimism. Not only in temperate zones, but in many parts of the tropical world as well, with the notable exception of small rainfed cropping systems, the use of synthetic pesticides and to a lesser extent of herbicides became standard practice. Total crop devastation, that powerful biblical image, seemed a thing of the past.

However, we are all too familiar with the world wide disappointments that followed. Soon, a gradual but unhalting stream of criticism was published in both the scientific and public arenas. The disappointments originated in two diverse fields, the biological and the social sciences. In Asia's irrigated rice systems, the green leafhopper and the brown plant hopper emerged as major plant protection problems. The socio-economic inequity associated with the introduction of modern technology - competition for land, irrigation water and credit - soon became apparent as well. In Latin America, land tenure and civil strife delayed much of the development. From Africa, we heard very little, if anything at all, and attempts to promote anything comparable to a Green Revolution failed, with the exception of maize in East Africa. At the same time, economists pointed to the rapidly 
rising costs of agricultural subsidies and the negative effects of protectionism for the world as a whole.

Nevertheless, agricultural science was able to adjust and broaden its goals, even if it took some time to accept that the period of relatively easy successes was over. In Northwestern Europe and North America, concerns about the excessive use of pesticides, and, somewhat later also of chemical fertilizers, and their effects on the environment set into motion a tremendous search for alternative crop protection measures. In agronomy, we have witnessed a focus on resource use efficiency, to obtain most efficient production levels per unit of input while minimizing the emissions to the environment. Thanks to the social sciences new approaches took hold, some more permanent than others, like farming systems research. There is general agreement today that not only yield, i.e. production per unit area and time, but a multitude of other considerations have to be included in technology development.

Again, as in the earlier stage of the Green Revolution, crop protection specialists were among the first to explore new and interdisciplinary approaches and to acknowledge the need for participation of farmers, not in the least women, in the monitoring and application of pest, pathogen and weed control. It is worth noting that possibly because of the complexities of the environment, agricultural scientists working in the tropics have been more advanced in applying an integrated and systems approach than those in temperate zones.

And yet, if in the course of the 1980s agricultural science has shown sufficient flexibility to deal with new goals, somehow a deep rift has emerged between scientists, political decision makers and the general public. In many countries the political and administrative powers ignored scientists' warnings about the risks of the widespread use of chemicals in agriculture and the pleas for appropriate measures - until it was nearly too late. The generation that has now come to power is dominated by well-fed male professionals with an urban background, who have hardly any connections with the agricultural sector. For them, as well as for the general public, the agricultural sector is no more than a producer of surpluses of cheap food, that pollutes the environment and poses a threat to the landscape and to biodiversity. A strange inconsistency has overtaken the public mind, particularly in the west, used to having their cake and eating it too. There is a general abhorrence of agricultural production based unfortunately on rather naive ideas about ecology. Along with genetic engineering and bio-industry, chemicals for crop protection, once a blessing, are now singled out as examples of agricultural horror stories. On the other hand, the genuine support for and awareness of ecological issues is unprecedented. And yet North European consumers prefer tomatoes from the Mediterranean because they are lower priced, thereby choosing to ignore that these are often grown with considerable amounts of chemicals without measures to protect the environment. It is a similar inconsistency that makes people blind to the fact that the nature conservation which they so ardently support presupposes a healthy and productive agricultural sector. Without agricultural production there can be no land for nature.

If things appeared relatively simple 25 years ago, and started to become complicated in the 1980 s, the coming decades will bring more headaches. First there is the sheer production challenge based on the well known demographic projections: about 8.5 billion people in 2025 , with 7 billion in what we currently call developing countries. More than half of the world population will be city dwellers. A cereal deficit has to be counted with of 240 million tons (IFRPI) or 400 if malnutrition is to be banned completely (CGIAR). This implies a more than doubling of the production in developing countries. Nearly all of that increase must be reached by increasing land productivity. And on this planet, at non-geological time scales, land is an irreplaceable resource. 
We face the fact that the growth in aggregated cereal output has declined since 1982. The main factors associated with this are the decline in the performance of irrigation systems, increased losses due to pests, diseases and weeds, inefficient fertilizer use, soil mining in rainfed annual cropping and, in my view one of the underestimated factors, the enormous expansion of agriculture onto more marginal and fragile environments. Coupled with deteriorating terms of trade, individual farmers have few if any opportunities to invest in maintaining the productive qualities of their land. Soil mining is the only solution for many smallholders in the rainfed tropics. But even in the temperate zones, particularly in Eastern Europe, the new economic order does not allow investments to strengthen the productive capacity of the land, to protect the harvest or to obtain healthy planting material.

Recent detailed estimates (Oerke et al. 1994) point to pre-harvest crop losses of about $40 \%$, and losses during and after harvesting of 10-30\%. Accordingly, more than a staggering $50 \%$ of produce grown for consumption is lost. To reduce this figure is one of the most important production challenges.

Furthermore, future global change may seriously influence the distribution of land use across the globe, with possible negative yield effects in the tropical and Mediterranean climate zones. The rapid human induced changes in land cover and their effects in terrestrial ecosystems and the enhanced greenhouse conditions are still poorly understood, but significant in all global change models.

But production increase, however important, is not our only challenge anymore. The Brundlandt report "Our common Future", UNCED in Rio, as well as various other international conferences brought to the fore the well being of future generations. Even if these ideas were not original, they have gained wide acceptance and have further strengtened the shift in scientific goals from production increase and resource use efficiency to sustainability. However we define that exactly, it implies an agriculture which among many other things also protects the natural resource basis. In other words, a new Green Revolution, for which the term Supergreen has been coined. It means no less than designing new agricultural systems to meet new consumer standards on quality, which at the same time are complementary to the demands of nature conservation, recreation, urban and landscape development.

What do these challenges imply concretely for agricultural production systems across the world? Let me just highlight three, somewhat arbitrarily selected situations.

1. Let us start with the systems that employ most people, the lowland cereal based systems of Asia: highly intensive, high labour and biochemical input demanding smallscale systems based on complex crop associations and rotations. Competition with urban expansion and industry will become even more severe, leading to even further intensification here. The stable provision of cheap bulk carbohydrates for the urban masses will be essential, but so will be the income earning opportunities of small farmers. In Southeastern Asia the area cultivated per person will decline to a staggering 0.09 ha in 2025. Furthermore, we should worry about the fact that in hitherto successful Green Revolution areas such as the Punjab, rice yields are stagnating, despite the continued increase in yield at aggregate national levels. Total factor productivity indexes based on constant prices have remained flat or have even become negative over the past 25 years. We can only speculate about the causes of these trends and they merit further study.

These lowland systems are characterized by an enormous gap between production potential and actual yields. Average nitrogen applications in Asia for all crops amounts to only $30 \mathrm{~kg} / \mathrm{ha}$ annually. While this contrasts favourably with $15 \mathrm{~kg}$ in Latin America 
and a mere $4 \mathrm{~kg}$ in Africa, and the figures are higher for irrigated crops, application rates today are too limited to sustain intensive multiple cropping systems. Adequate nutrient management will require considerable attention. Weed control will become a pressing issue, as a result of the increased use of direct seeding and the rising wage rates.

Without doubt the needs for crop protection will increase as land use intensifies, in particular under monocultures, and new pest and disease problems are likely to emerge. Crop protection specialists will have to cooperate closely with other disciplines such as physiologists. A case in point is the current work at IRRI on new plant types with enhanced grain filling and resistance to pests and diseases. It has been amply demonstrated that, without spraying during the first 40 days of rice growth, beneficial insect populations are kept at adequate levels for pest control - with major benefits to farmer health and income as well as to the environment. If the success of IPM is to continue, it has to be extended to other pests and pathogens and to weeds. Also, the role of field borders and small patches of 'common' land as habitats for useful species in pest control requires further study especially with mounting land pressure. The main point to retain is that IPM cannot be carried out on isolated fields but requires a concerted technical and social action that extends well beyond the local level. Finally, the protection of the remaining areas under natural vegetation will demand adequate legislative measures - up till today, rainforests are being transformed into arable land for cash crops.

\section{At the mid-latitudes of North America, Australia, Northwestern and Eastern Europe} we find a highly mechanised agriculture characterized by low labour/land ratios dominated by cereal and potato production. These are the monotonous landscapes that have been profoundly modified by agriculture and related administrative measures. Yield projections and expectations of trade liberalization suggest strongly that considerable areas of land may be taken out of production during the coming decades and converted to other purposes. This trend will be less pronounced in Eastern Europe where yields are still lower. While bulk cereal production will continue in the less densely populated parts, increased diversification may be desirable elsewhere. Soil-borne pests such as nematodes may further stimulate such a trend towards rotational systems. Reafforestation of former agricultural lands or tree-crop combinations (a temperate version of agro-forestry) may provide interesting alternatives, probably not from an economic but possibly from an ecological viewpoint. In all cases, consumers will impose an increased emphasis on product quality and the production situation. I expect that this will move conventional agriculture in the direction of today's so-called ecological agriculture. But one which uses the most modern methods of expert-based prediction systems for fertilizer need and crop damage control. This type of "precision farming" is currently mainly developed by soil scientists and agronomists, and integration of crop protection will be a challenge. The main bone of contention is to what extent agriculture should be concentrated in the most favourable areas. From a technical point of view we may expect higher efficiencies and fewer emissions in well endowed areas, but this may not always be acceptable from a rural development perspective. What role farmers in more marginal areas should play is another unresolved issue. The outcome of current programmes to promote the integration of farming and nature or landscape conservation will determine some of the future plans in this respect.

3. The third case I want to dwell upon briefly are partially or fully irrigated systems (around the Mediterranean, in Kazachstan, Chile, California, etc.), sometimes cereal based, but mostly specialised, export oriented systems such as orchards, cotton plantations and horticulture. As these systems are rather costly, certainly from an ecological point of view, if we include the real price of water and the risks of 
salinization, quality based competition may be the only solution. The expected freshwater shortages in many semi-arid and arid climates will make efficiency of water use a major issue. In many horticultural systems the exaggerated use of chemical control is currently promoted by its easy accessibility and relatively low price, but this will hopefully change. From a sustainability perspective, we need to explore trade-offs in the area of erosion control between e.g. zero tillage which requires herbicides and the alternative of no erosion control leading to silting of reservoirs and loss of precious top soil. Other challenges here are the judicial use of irrigation water, in particular in combination with chemicals for crop protection, especially given the requirements for drinking water in neighbouring urban areas and tourism. It would seem that biological control, especially in the dry season when very little vegetation survives outside the irrigated fields, requires major efforts. The use of alternative habitats for beneficial pests such as mulch or grass strips in orchards may provide interesting possibilities. High labour costs are likely to speed up the rate of mechanisation. Preventing land degradation and safer labour conditions will become crucial issues in the future. These three simple cases exemplify the widely contrasting socio-economic and biophysical conditions in which production systems operate and the variability between and within systems in the same zone. These defy any attempts at looking for the equivalent of wide adaptability as we did long ago.

However, the challenge is not only to combine the goals of production increase and sustainability, but to rethink agricultural systems as a whole. For crop protection this implies thinking about integrated protection of production systems rather than integrated pest or crop management (as it is still called according to the acronym and the theme of this congress).

By Integrated Protection of Production Systems I mean the following:

- Integrating the protection against all types of biological threats to plants, due to weeds, pathogens, pests, viruses, viroids, and so on.

- Integrating the different disciplines, and in particular linking ideas from soil science and agronomy to crop protection, but also continuing the integration of socio-economic concerns. There seems tremendous scope to integrate IPM (Integrated Pest Management) and INM (Integrated Nutrient Management).

- A focus on larger spatial and temporal units than just the individual field in a single season, with due attention to habitat protection and watershed management. In other words, we ought to try to integrate the farmers field in the wider landscape. Enhancing the sustainability of land use in a broad sense requires an awareness of the scales at which different ecological and socio-economic processes operate.

- Integrating the different demands on land: agricultural production, landscape and nature conservation, tourism, etc.

- Promoting the integration and participation of land users: farmers, decision makers and the general public.

Because that last point is perhaps our ultimate challenge, the term 'integrated protection of production systems' that I just coined can also be taken to mean safeguarding the primary production sector in our societies. I would venture that agricultural science may be facing its worst crisis ever. Far worse than the critisms raised about the Green Revolution, far worse than the debate about pesticides. Today, the credibility and usefulness of agriculture itself are in doubt at a point in time that the need for major concentrated action is more apparent than ever.

Yet I wonder how many of you would advise your children to study agricultural science today. Biology perhaps, but agricultural science? Nearly without exception, all over the world numbers of students in the agricultural sciences are steadily declining. 
Some would even say that their quality is also lowering, because the brightest minds are increasingly attracted to computer science or mathematics or engineering. Incidentally, this is also the case in nations where agricultural still provides employment to a sizable part of the population, in Africa or Asia.

So we are facing a dual challenge: to broaden our scope to develop a sustainable basis for production systems and to rethink the place of the agricultural sector and of agricultural science. The sad irony is that at a time that the biological productivtity of the globe is more in question than ever before, the science concerned with harnessing the primary and secondary production to satisfy human needs has fallen from grace. I can only conclude that this dual challenge demands a deep commitment from everyone of us.

\section{References:}

Oerke, EC, HW Dehne, F. Schönbeck, A. Weber: 1994. Estimated losses in major food and cash crops. Amsterdam, Elsevier: $830 \mathrm{pp}$. 